ployed at St. Bartholomew's, Carr's apparatus being used instead of two straight splints. This consists of a splint for the flexor aspect, somewhat thinned at the wrist in order to fit it, and having obliquely fixed to its end a piece of ruler sufficiently long to be conveniently grasped in the hand. There is also a small straight splint for the extensor aspect. It is applied in the following way: Reduction is effected in the usual manner, and then the hand is made to grasp the palmar piece, and fixed by a turn or two of bandage. The extensor splint is then applied, and the whole firmily bandaged and put in a sling. Before application the splints are padded with a double layer of lint. The object of this splint is to overcome the displacement towards the radial side, and also for convenience in getting early movement of the fingers, and so to prevent stiffness.

Before going on to the subsequent treatment, a practical point may here be mentioned; namely, the importance of getting very good position in these fractures, since, if deformity is left, it not infrequently causes considerable interference with the utility of the hand. Even at St. Bartholomew's, with plenty of assistance obtainable, it is sometimes found necessary to give an anæsthetic for this purpose.

3. Stiffness of the fingers is a difficulty that has to be continually thought of in treating this fracture. It is usual at St. Bartholomew's in using the simple straight splints, to examine the condition of the bones at about the end of five days to a week, in order to see that they are in good position, and this opportunity is also generally taken of shortening the splint on the flexor aspect, so that it reaches only to the metacarpo phalangeal joints in order that passive movement of the fingers may be begun.

At the end of another fortnight the extensor splint may also be shortened, and passive movement tried at the wrist joint if there seems to be some firmness in the fracture. If Carr's splint has been used it is usual to free the fingers from their bandage at about the end of a week. All apparatus is generally given up at about the end of the fourth week, the arm being then simply enclosed in a bandage, and kept in a sling for about another week. A good deal of stiffness is usually left, and this is treated by friction, in order to facilitate which some form of liniment is given, such as the Linimentum Saponis of the Pharmacopœia. By several of the surgeons the treatment of the remaining stiffness is thought to be best carried out by bathing the arm and hand in water as hot as can be conveniently borne, then in the bath carrying out forcible passive movement as much as the patient will allow. After the bath the limb is thoroughly rubbed with the liniment. Should the stiffness not yield to this treatment, it has in some cases been advised to give an anæsthetic, such as nitrous oxide gas, and break down the adhesions which are giving most trouble by force, and subsequently carrying on the treatment by douches and frictions.

\section{CENTRAL LONDON THROAT AND EAR HOSPITAL.}

The Treaturent of Post Nasä adenoids.

In dealing with the treatment of inflammatory diseases of the middle ear, we must remember that speaking generally, there are four varieties of inflam. mation which occur in this situation-namely, acute and chronic non-suppurative, and acute and chronic suppurative catarrh.

Before, however, saying anything as to the treatment of each of these classes of cases, it will be most convenient to speak of the treatment of the conditions of the pharynx, and naso-pharynx, on which the occurrence of these inflammations so frequently depend-. namely, adenoid vegetations and enlarged tonsils.
At the Central London Throat Hospital the removal of adenoid vegetations and tonsillotomy are usually done in the out-patient room, unless the patient lives

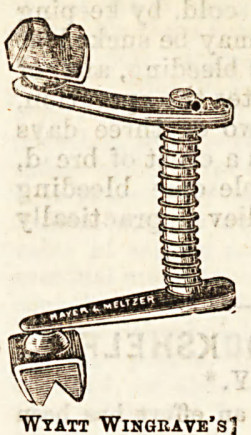
at too great a distance, in which case he may be taken into the hospital for a time. The patients are, it need hardly be said, in the majority of cases children. The method adopted is as follows: The mouth is kept open by means of a gag, which can be easily moved to either one side or the other (see diagram), and the nitrous oxide gas is administered. So soon as the patient is well under, the tonsils are removed by means of a Macken. zie's guillotine, or, if they should

WratT WINGRAVE's 1 be of very large size, by means of much reduces the size of the bleeding surface. If the écraseur be used the anæsthesia does not last long enough, so it is the more usual to remove the tonsils first, without an anæsthetic, and then give gas afterwards for the adenoids.

The adenoids are dealt with in two or three different ways, according to the operator. One way is to use curettes of different shapes, passed up behind the soft

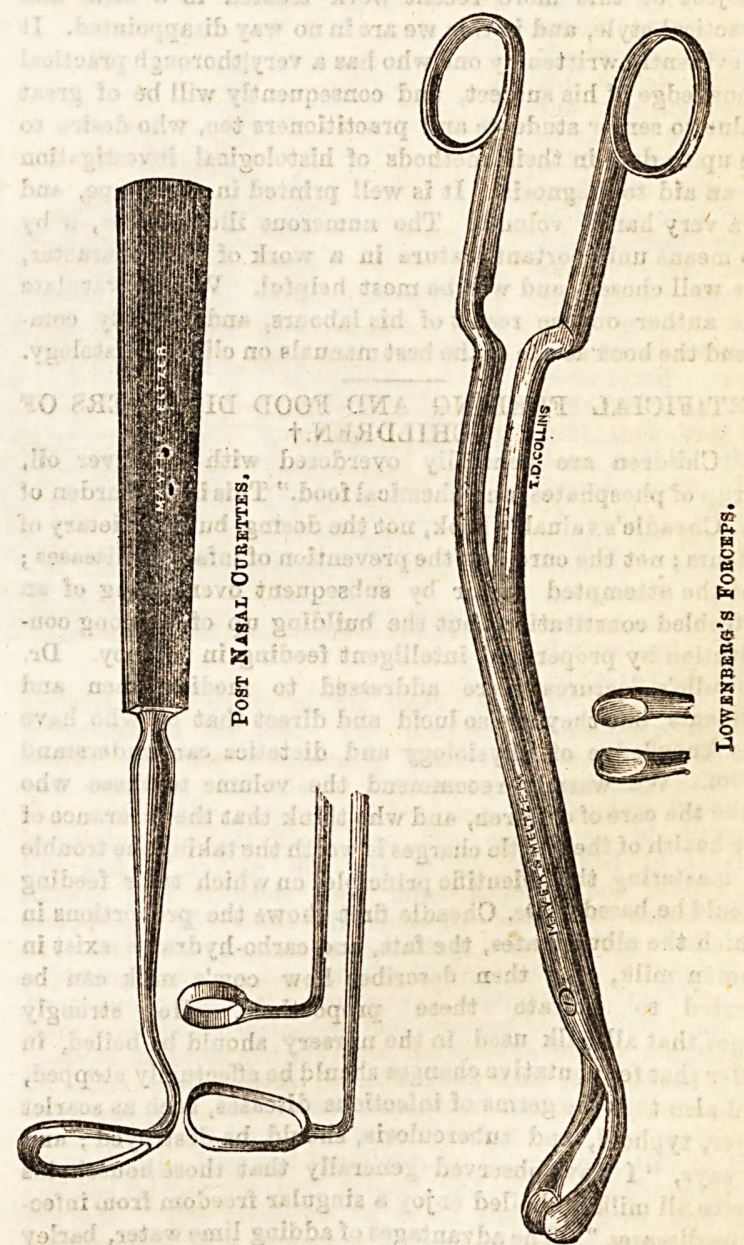

palate, or else the growths may be first scraped together with the finger-nail, and then the mass removed by Lowenberg's forceps. Whichever method be used, the last part of the operation always consists in a free scraping with the finger-nail.

The advantage claimed for the use of gas, over chloroform or ether, is that, as the patient comes round 
immediately, he is able, by coughing, to materially assist in preventing blood and débris from passing into the trachea. The after-treatment consists in preventing the patient from being exposed to cold, by keeping him indoors for about a week. Ice may be sucked at first, as it relieves pain and prevents bleeding, and, of course, the food must, immediately after the operation, consist entirely of slops, and for two or three days should contain nothing rough, such as a crust of bread, to irritate the raw surface. Troublesome bleeding from the tonsil wound is, we believe, practically unknown at the Central London. ( $T$ o be continued.)

\section{THE PRACTITIONERS' BOOKSHELF. MEDICAL MICROSCOPY.*}

The author states that in this work an effort has been made to lay before practitioners and students the most simple methods of preparing microscopic sections, and of the examination of urinary deposits, sputa, blood, \&c ; while, at the same time, for those who wish to extend their studies further, more elaborate methods have been detailed, and chapters added on the examination of food and bacteriological methods. From a joint author of the excellent "Clinical and Practical Pathology" we should expect to find the subject of this more recent work treated in a clear and practical style, and in this we are in no way disappointed. It is evidently written by one who has a verylthorough practical knowledge of his subject, and consequently will be of great value to senior students and practitioners too, who desire to be up to date in their methods of histological investigation as an aid to diagnosis. It is well printed in clear type, and is a very handy volume: The numerous illustrations, a by no means unimportant feature in a work of this character, are well chosen, and will be most helpful. We congratulate the author on the result of his labours, and heartily com. mend the book as one of the best manuals on clinical histology.

\section{ARTIFICIAL FEEDING AND FOOD DISORDERS OF CHILDREN. $\dagger$}

"Children are generally overdosed with cod liver oil, syrup of phosphates, and chemical food." This is the burden of Dr. Cheadle's valuable book, not the dosing, but the dietary of infants ; not the cure, but the prevention of infantile diseases ; not the attempted repair by subsequent overfeeding of an enfeebled constitution, but the building up of a strong constitution by proper and intelligent feeding in infancy. Dr. Cheadle's lectures were addressed to medical men and students, but they are so lucid and direct that all who have any knowledge of physiology and dietetics can understand them. We warmly recommend the volume to those who have the care of children, and who think that the insurance of the health of their little charges is worth the taking the trouble of mastering the scientific principles on which their feeding should be based. Dr. Cheadle first. shows the proportions in which the albuminates, the fats, and carbo-hydrates exist in human milk, and then describes how cow's milk can be treated to imitate these proportions. He strongly urges that all milk used in the nursery should be boiled, in order that fermentative changes should be effectually stopped, and also that the germs of infectious diseases, such as scarlet fever, typhoid, and tuberculosis, should be destroyed; and he says, "I have observed generally that those households where all milk is boiled enjoy a singular freedom from infectious diseases." The advantages of adding lime water, barley water, bicarbonate of soda, and cream, are discussed, and exact instructions given; also the value of peptonised milk, condensed milk, and artificial human milk. The *"Medical Microscopy," By Franx WeThered, M.D.Lond. Illas-
truted: Pp. 400, (Lew1s, London.) trated: Pp. 400. (Lewis, London.)

†'Artificial Feeding and Food Disorders of Ohildren." By W. B. OHEADLE, M.A., M.D. Oantab, F.R.O.P. (Smith, Elder, and Oo., conditions under which other artificial foods must be used are then described, and the preparation and uses of bread jelly, and raw meat juice are clearly given. Dr. Cheadle points out how starch foods, such as arrowroot and corn.flour, are inadmissible for infants, who have not the power of digesting starch till they are six months old; and that even the much-vaunted malted foods-in which the starch is changed into dextrine-are absolutely unsatisfactory unless taken with milk. The colic, flatulence, and diarrhœa of bottle-fed children are due to incorrect feeding, and when a child is seen to suffer or to do badly on one artificial food or one kind of milk, it is not enough to suddenly put it on another, but to study the causes of failure and to ascertain by a correct knowledge of food values the element deficient in the infant's diet. "The occurrence of rickets," says Dr. Cheadle, "is too often a grave reflection upon medical man, or nurse, or mother, under whose directions the diet of the child has been regulated." Want of knowledge can nowadays be no excuse for the infliction of suffering, and an opportunity to know how to diet infants and to ensure their health, is given by Dr. Cheadle's admirable book, and should be taken advantage of by all intelligent persons having the care of infants.

\section{IN MEMORIAM.}

JOHN CHARLES STEELE, M.D.

For forty years Medical Superintendent of Guy's Hospital.

And he is gone! The man of honest heart,

Whose voice for truth and right was ever heard,

The man who ever chose the better part,

Nor spoke an unkind word.

How we shall miss the dear benignant face

We knew so well within the grey old square.

Guy's will appear to all another place,

If he may not be there.

Calmly he sees the evening shadows fall,

The labourer rests at setting of the sun.

He hears - we cannot hear - the Master's call

"Servant of God, well done."

Around thy grave the weeping mourners stand

In grief bowed down. Ah! What shall break the spell? Accept this heartfelt tribute from the hand

Of one who loved thee well.

\section{BOOKS RECEIVED}

\author{
SMith, ERder, aNd Oo. \\ "Oroonian Lectures for 1892." Bg Sir W. Roberts, M.D. \\ 0. Grifrin and Oo.
} "A Manual of Inorganic Ohemistry." By A. Dupré, Ph.D., and H
Wilson Hake, Ph.D.

Kegan PaUL, Trench, aNd Trubner.

"First Aid in Illness and Injary." By James E. Piloher, M.D. Oambridge University Press. "Atlas of Olinical Medicine," Vol. II., Part I. By Byrom Bramwell,
M.D.

Swan Sonnenscheis and Oo.

"Geographical Distribation of Disease in Great Britain." Bg Alfred Haviland, M.R.O.S.

"Introduction to the Stady of Klementary Biology." By H. J. Oampell, M.D.

"Tae Socia Horizon." By the anthor of "Life in Oar Villages."

"Introduction to Physiologioal Prychology." B Dr. T. Ziehnen. "Tear Hertwig ; translated by Edward $\mathrm{M}$ irk, Ph.D.

Periodicals and Pamphlets.

Religious Tract Societr.-The Sunday at Home, The Girl's OWh Pager, The Boy's O wn Paper, Tae Leisure Hour, Friendly Greotings.

\section{Other Publications.}

Advice to Women on she Oare of their Health during and after Oon. finement, by Florence Stacpoole; Our Sick and How to Take Oare of Them, or Plain Teaching on Sick Nuring at Home, bJ Record of Thoole; The Medical Magazine; The Rural Worla; The Ther ot Tuchnical End Secondary Eoucation, for November; The Ther pist; The Olinical Journal; R porb of the Medical and Surgical cinses at the London Tem oerance Hospital for three years; The Vac. Review of Reviews; The Practical Side of Scientiflo Tempersnce. The 